\title{
Reply to a letter
}

\author{
Ha Yeon Kim ${ }^{1}$ · Jin-Soo Kim ${ }^{1}$
}

Received: 27 April 2020 / Accepted: 3 May 2020 / Published online: 14 May 2020

(c) Japanese Society of Anesthesiologists 2020

Keywords Duration $\cdot$ Intermediate cervical plexus block $\cdot$ Ropivacaine

\section{To the Editor:}

We maintained a shallow depth of anesthesia during the intermediate cervical plexus block (ICPB) procedures, so as not to delay the patients' wake-up times. As a result of review of the records, the duration from termination of blockade to the end of anesthesia was within $15 \mathrm{~min}$ in all patients, and the distance from the operating room to the post-anesthesia care unit (PACU) was only a few min walking distance. We measured the first diaphragmatic motion when the patients were fully cooperative. Postoperative nausea and vomiting, as well as pain, were well controlled, and hence, these symptoms did not interfere with the measurement of diaphragmatic motion.

The analgesic effect of $0.2 \%$ ropivacaine lasts for $5-16 \mathrm{~h}$ [1]. The duration of action of ropivacaine is affected by the concentration, the local tissue conditions, and the site of injection, but not the plasma half-life [1]. In our study, a loss of cold sensation in the neck and chest persisted for over $1 \mathrm{~h}$ after the patients were admitted to the PACU, which means that the effect of the ICPB had not dissipated $60 \mathrm{~min}$ after admission to the PACU. In addition, a previous report found that it took $30 \mathrm{~min}$ for hiccups to disappear after a $10 \mathrm{ml}$ injection of the $0.2 \%$ ropivacaine directly targeting the phrenic nerve [2]. Therefore, we believe that an ICPB using $0.25 \%$ ropivacaine of $0.2 \mathrm{ml} / \mathrm{kg}$ at the $\mathrm{C} 4-5$ intervertebral level did not cause ipsilateral hemi-diaphragmatic paresis.

\section{Compliance with ethical standards}

Conflict of interest The authors declare that they have no conflict of interest.

\section{References}

1. Gadsden J. Local anesthetics: clinical pharmacology and rational selection. In: Hadzic A, editor. Peripheral nerve blocks and anatomy for ultrasound-guided regional anesthesia. New York: McGraw-Hill Education; 2012. p. 29-40.

2. Kang SS, Jang JS, Park JH, Hong SJ, Shin KM, Yun YJ. Unilateral phrenic nerve block guided by ultrasonography and nerve stimulator for the treatment of hiccup developed after tongue cancer operation: a case report. Korean J Anesthesiol. 2009;56:208-10.

Publisher's Note Springer Nature remains neutral with regard to jurisdictional claims in published maps and institutional affiliations.

This reply refers to the comment available online at https://doi. org/10.1007/s00540-020-02786-8.

Jin-Soo Kim

jskane@ajou.ac.kr

1 Department of Anesthesiology and Pain Medicine, Ajou University School of Medicine, 164 World cup-ro, Yeongtong-gu, Suwon 16499, Republic of Korea 